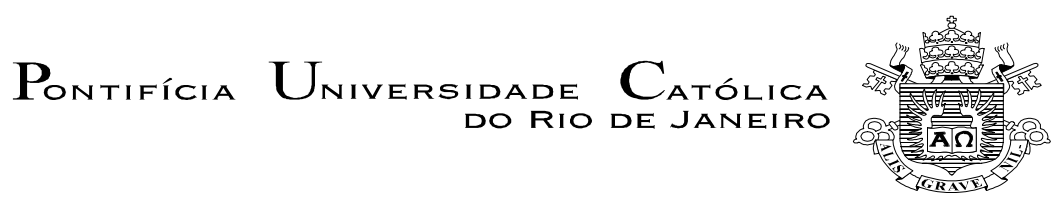

Fernanda Rivas Filipe

Mas não teria sido mais fácil se você tivesse oferecido um modelo de plano de aula? Repensando a construção do plano de aula.

Dissertação apresentada como requisito parcial para obtenção do título de Mestre pelo Programa de Pós-Graduação em Letras da PUC-Rio.

Orientador: Prof ${ }^{\mathrm{a}}$. Dra . Inés Kayon de Miller

Rio de Janeiro, março de 2009 
Pontifícia

Universidade CATǴlica $_{\text {Do Rio de Janeiro }}$

Fernanda Rivas Filipe

\title{
MAS NÃO TERIA SIDO MAIS FÁCIL SE VOCÊ TIVESSE OFERECIDO UM MODELO DE PLANO DE AULA?
}

Repensando a construção do plano de aula

\begin{abstract}
Dissertação apresentada como requisito parcial para obtenção do título de Mestre pelo Programa de PósGraduação em Letras do Centro de Teologia e Ciências Humanas da PUC-Rio. Aprovada pela Comissão Examinadora abaixo assinada.
\end{abstract}

Profa. Inés Kayon de Miller
Orientador
Departamento de Letras -PUC- Rio

Profa. Beatriz de Castro Barreto Departamento de Letras -PUC-Rio

Prof ${ }^{\text {a }}$ Isabel Cristina Rangel Moraes Bezerra UERJ

Prof. Paulo Fernando Carneiro de Andrade Coordenador(a) Setorial do Centro de Teologia e Ciências Humanas - PUC-Rio

Rio de Janeiro, 27 de março de 2009. 
Todos os direitos reservados. É proibida a reprodução total ou parcial do trabalho sem autorização da universidade, da autora e do orientador.

\section{Fernanda Rivas Filipe}

Graduou-se em Letras (Português/Inglês) na UFF (Universidade Federal Fluminense) em 1995. Cursou Especialização em Lingüística Aplicada ao Ensino de Língua Inglesa como Língua Estrangeira em nível de Pósgraduação "lato Sensu" de março de 1996 a dezembro de 1996 na UFF e Especialização em Psicopedagogia na UCAM (Univerisdade Cândido Mendes) de agosto de 2004 a agosto de 2005.

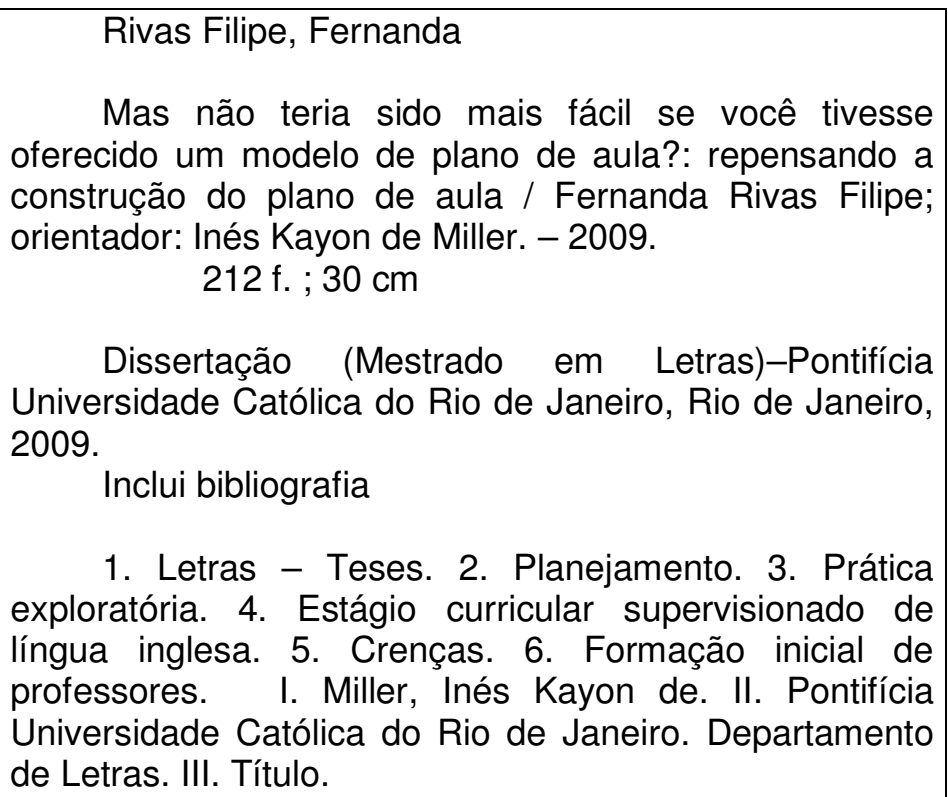

Mas não teria sido mais fácil se você tivesse oferecido um modelo de plano de aula?: repensando a construção do plano de aula / Fernanda Rivas Filipe; orientador: Inés Kayon de Miller. - 2009. $212 \mathrm{f}$; ; $30 \mathrm{~cm}$

Dissertação (Mestrado em Letras)-Pontifícia Universidade Católica do Rio de Janeiro, Rio de Janeiro, 2009.

Inclui bibliografia

1. Letras - Teses. 2. Planejamento. 3. Prática exploratória. 4. Estágio curricular supervisionado de língua inglesa. 5. Crenças. 6. Formação inicial de professores. I. Miller, Inés Kayon de. II. Pontifícia Universidade Católica do Rio de Janeiro. Departamento de Letras. III. Título. 
Aos meus pais.

À minha avó, Maria Presentación Rodrigues Garcia (in memorian), por seu amor e por ter me ensinado o que nenhuma escola ensinaria: respeito, paciência, persistência, vontade e coragem. À minha irmã Fátima Cristina Rivas Filipe de Oliveira, pelo apoio. 


\section{Agradecimentos}

A Edson da Costa Ribeiro, por ter acreditado em mim.

Ao amigo Sebastião Gomes dos Santos Filho que me apresentou a PUC-Rio.

Às amigas de Mestrado, Mariluce Filizola Carneiro Pessoa e Mônica de Medeiros Villela, por compartilhar momentos de aflição e por nossos cafés sempre tão enriquecedores.

À Maria Luísa Furlin Bampi, diretora da FAFIMA, que permitiu a utilização do nome da instituição e de documentos importantes para este trabalho.

Aos professores-aprendizes da turma de Estágio Curricular Supervisionado de Língua Inglesa do $2^{\circ}$ semestre letivo de 2007, que gentilmente cederam o direito de utilização de seus trabalhos para esta dissertação.

A todos os professores de minha vida de estudante.

Ao Departamento de Letras da PUC-Rio e, em especial, a Francisca Ferreira de Oliveira, Secretária da Pós-Graduação, pela eficiência e paciência sem fim.

À PUC-Rio, pelo apoio financeiro, sem o qual não seria possível a realização de meu sonho.

E, de forma muito especial, à Prof $^{a}$. Dr ${ }^{a}$. Inés Kayon de Miller, minha orientadora, professora-exploratória, com quem tenho compartilhado um enorme prazer em aprender. 


\section{Resumo}

Rivas Filipe, Fernanda; Miller, Inês Kayon de. Mas não teria sido mais fácil se você tivesse oferecido um modelo de plano de aula? Repensando a construção do plano de aula. Rio de Janeiro, 2009. 212p. Dissertação de Mestrado - Departamento de Letras, Pontifícia Universidade Católica do Rio de Janeiro.

O objetivo desta dissertação foi aprofundar meus entendimentos acerca do processo de construção do plano de aula e entender como os professoresaprendizes viam o ato de planejar. É fruto de um trabalho exploratório realizado em minha própria turma de Estágio Curricular Supervisionado em Língua Inglesa no contexto de uma Instituição de Ensino Superior durante o primeiro bimestre do segundo semestre letivo do ano de 2007. Para atender a esse propósito, foram analisados os dados obtidos por meio de duas Atividades Pedagógicas com Potencial Exploratório (APPE): uma discussão realizada no primeiro dia de aula sobre as características dos professores de língua inglesa desse novo século (registradas em transparências) e um relatório escrito pelos professores-aprendizes no fim do curso, no qual narraram ou descreveram como foi o processo de construção do plano de aula. A percepção de que os professores-aprendizes se utilizavam de seus sistemas de crenças, consciente ou inconscientemente, para planejar suas aulas, levou-me a elaborar este trabalho tendo como base os princípios da Prática Exploratória. Minha dissertação visava entender com mais profundidade a natureza do ato de planejar e a qualidade da vida na sala de aula de Estágio Curricular Supervisionado, buscando, para tal, preencher uma lacuna no campo da formação inicial de professores de língua inglesa dada à escassez de teorias que partam da prática profissional do professor-investigador nessa área.

\section{Palavras-chave}

Planejamento; Prática Exploratória; Estágio Curricular Supervisionado de Língua Inglesa; crenças; formação inicial de professores. 


\section{Abstract}

Rivas Filipe, Fernanda; Miller, Inés Kayon de (advisor). "But wouldn't it have been easier if you had offered us a model of a lesson plan?" Rethinking the construction of lesson plans. Rio de Janeiro, 2009. 212p. Dissertação de Mestrado - Departamento de Letras, Pontifícia Universidade Católica do Rio de Janeiro.

The objective of this dissertation was to enhance my understanding about the process of construction of lesson plans and understand how teacher-learners view planning. This is the result of an exploratory practice process performed with my own group of English Language Teaching Practice in the context of a Higher Education Institute during the first bimester of the second term in 2007. In order to achieve this aim, two Potentially Exploitable Pedagogic Activities (PEPAs) were developed: a discussion held on the first day of classes about the characteristics of English teachers in the new century (registered in OHTs) and the teacher-learners' end-of-term written report, in which they narrated or described their personal understandings of how the lesson plan construction was developed. All the generated written data were gathered and analyzed. The perception that, in order to plan lessons, teacher-learners used their belief system, at a conscious or unconscious level, led me to the construction of this

practitioner research work. Oriented by the principles of Exploratory Practice, I also based my analysis on studies on teacher and learner beliefs as well as on pre-professional teacher preparation. My dissertation aimed at deepening my understanding on the nature of planning and the quality of life in my English Language Teaching Practice classroom, seeking to fill a gap in the area of preprofessional English teacher preparation on account of the scarcity of theories that derive from teacher-research of professional practices in this field.

\section{Keywords}

Planning; Exploratory Practice, English Language Teaching Practice; beliefs; pre-professional teacher preparation. 
"A principal ferramenta de trabalho do professor é sua pessoa, sua cultura, a relação que instaura com seus alunos, individual ou coletivamente. Mesmo que a formação esteja centrada nos saberes, na didática, na avaliação, na gestão de classe e nas tecnologias, nunca se deve esquecer a pessoa do professor. No entanto, os formadores ainda devem adquirir as competências necessárias para se aventurarem com confiança nesse registro". 


\section{Sumário}

1 Introdução 13

1.1 interesse na formação inicial de professores 15

1.2 Estágio Curricular Supervisionado em Língua Inglesa:

$\begin{array}{ll}\text { entendimentos iniciais } & 17\end{array}$

$\begin{array}{ll}1.3 \text { Por que o foco no planejamento? } & 17\end{array}$

1.4 Por que tentar interpretar o discurso dos professores-aprendizes $\begin{array}{ll}\text { tendo como base o estudo de crenças? } & 18\end{array}$

1.5 Apresentação de minha pesquisa 19

2 O contexto teórico que orientou minha pesquisa 21

2.1 Estudos sobre crenças: breve revisão bibliográfica 21

$\begin{array}{lll}2.1 .1 & \text { Visão adotada sobre crenças } & 24\end{array}$

2.2 Um olhar sobre a formação docente: linhas gerais 27

2.2.1 A formação do professor: histórico, problemas enfrentado e novos direcionamentos. $\quad 29$

2.2.2 Mudanças de perspectiva na formação do docente de LEs 33

2.2.2.1 A inclusão da pesquisa no curso de formação inicial de professores de língua inglesa 34

2.2.3 O que se espera dos cursos de Letras hoje? 37

2.3 Prática Exploratória (PE): um recurso para uma formação mais reflexiva do professor de Língua Inglesa 41

2.3.1 O que é a PE? 42

2.3.2 A PE no contexto de formação de professores 43

2.4 Estágio Curricular Supervisionado em Língua Inglesa: bases legais, implicações teóricas e novos direcionamentos 46 2.5 O que é planejar? 52

2.5.1 Planejar para controlar ou planejar para entender? 53

2.5.1.1 Planejar para controlar 54

2.5.1.2 Planejar para entender ('planning for understanding') 55 
2.5.2 Por que parece ser tão difícil planejar? - Tentando deixar de lado a noção de planejamento como controle

2.5.3 Enfim, para quê planejar?

2.6 Algumas considerações

3 O registro da experiência

3.1 Os contextos

3.1.1 Minha trajetória profissional 62

3.1.2 Os outros participantes 64

3.1.3 A Instituição de Ensino Superior 68

3.1.3.1 Perfil do curso e do graduado em Letras 69

3.1.3.2 O Projeto Político Pedagógico do Curso de Letras 70

3.1.3.3 Componentes Curriculares dos Cursos de Letras 71

3.1.3.4 Atividades Acadêmicas Articuladas ao Ensino de Graduação no Curso de Letras 72

3.1.3.5 Trabalho de Conclusão de Curso (TCC) 73

3.1.3.6 Importância da Prática como componente curricular e do Estágio Curricular Supervisionado

3.2 Estágio Curricular Supervisionado em Língua Inglesa (Ensinos Fundamental e Médio).

3.2.1 Ementa e negociação do programa de curso da disciplina Estágio Curricular Supervisionado em Língua Inglesa (Ensinos Fundamental e Médio).

3.3 Como foi que tudo começou? O processo de construção do plano de aula.

3.3.1 Um recorte: narrativa das aulas sobre a construção dos planos de aula

3.3.2 Outro recorte: as sessões de acompanhamento

3.3.3 Apresentação dos novos planos de aula no Laboratório de Práticas de Estágio Curricular Supervisionado

3.4 Atividades Pedagógicas com Potencial Exploratório (APPE) 93

\subsubsection{APPE 1}

\subsubsection{APPE 3 e 4}




\subsubsection{APPE 5}

4 Entendendo o que vi 98

4.1 Algumas considerações preliminares 99

4.2 O que é ser professor? Visão e crenças dos professores-

-aprendizes sobre o professor de língua inglesa do novo século. 100

4.2.1 O professor precisa ser high tech 100

4.2.2 O bom professor precisa ter domínio da matéria, criatividade, autoridade (respeito, limites e confiança) e cultivar o respeito professor vs. aluno.

4.2.3 O bom profissional precisa ser pesquisador e buscar aperfeiçoamento

4.2.4 Interação entre professor e aluno e estar presente

4.2.5 Conhecer a realidade do aluno e da classe como um todo e utilizar uma metodologia de acordo com os alunos

4.2.6 Preparar material didático com cuidado, passar para a classe de forma elucidativa e ser didático

4.2.7 Estabelecer critérios de avaliação e buscar uma avaliação constante e abrangente, visando antes a aprendizagem mas que a reprovação

4.2.8 Estrutura psicológica

4.2.9 Alguns entendimentos sobre essa primeira análise

4.3 É fácil. É difícil. Por quê?

4.3.1 Plano de aula: um bicho de "sete cabeças"

4.3.2 Plano de aula: a falta que um modelo faz

4.3.2.1 Como os professores-aprendizes viram a avaliação que realizei em seus planos de aula?

4.3.2.2 Sessões de acompanhamento: uma forma de ajudar e tornar os professores-aprendizes mais confortáveis com o que estavam fazendo 
6 Referências Bibliográficas

7 Anexos 